\title{
UV impacts avoided by the Montreal Protocol
}

Paul Newman

NASA, Goddard Space Flight Center, Greenbelt, MD 20771, USA

Richard McKenzie

National Institute of Water \& Atmospheric Research, NIWA Lauder, PB 50061

Omakau, Central Otago, 9352, New Zealand

For submission to Photochemical and Photobiological Sciences,

\begin{abstract}
Temporal and geographical variabilities in the future "World Expected" UV environment are compared with the "World Avoided", which would have occurred without the Montreal Protocol on protection of the ozone layer and its subsequent amendments and adjustments. Based on calculations of clear-sky UV irradiances, the effects of the Montreal Protocol have been hugely beneficial to avoid the health risks, such as skin cancer, which are associated with high UV, while there is only a small increase in health risks, such as vitamin D deficiency, that are associated with low UV. However, interactions with climate change may lead to changes in cloud and albedo, and possibly behavioural changes which could also be important.
\end{abstract}

\section{Introduction}

The Montreal Protocol on protection of the ozone layer has been one of the most successful environmental international agreements ever. Both the Vienna Convention and the Montreal Protocol have been ratified by all of the 196 countries in the world. Its implementation has resulted in large reductions of the concentrations of ozone depleting substances (ODSs, e.g., chlorofluorcarbons and halons). In addition, these ODSs are also potent greenhouse gases. Thus, in addition to its success in curbing ozone depletion, it has also mitigated a significant portion of the climate impacts due to increasing GHGs (especially $\mathrm{CO}_{2}, \mathrm{CH}_{4}$, and $\mathrm{N}_{2} \mathrm{O}$ ) that have occurred over the past two decades. ${ }^{1}$

Because of the success of the Montreal Protocol, only small decreases in ozone have occurred outside Polar Regions. A gradual recovery in ozone is expected over the next few decades. Consequently, any increases in UV radiation outside Polar Regions have been small and UV radiation is expected to decrease in the decades ahead. However, the longer term future is uncertain due to possible interactions with climate change, which will change atmospheric circulation patterns and stratospheric temperatures, affecting the geographical distributions of ozone and cloud clover. By the end of the century, these may lead to slight increases in UV in the tropics, but decreases at high latitudes. At mid latitudes, the future is less certain because the radiative impact of increases in ozone may be offset by the radiative impacts of decreases in cloud cover. ${ }^{2,3}$

Recently it was shown that without the Montreal Protocol, ozone column amounts at mid northern latitudes could have reduced from around $300 \mathrm{DU}$ to $100 \mathrm{DU}$ by 2065 , and that the corresponding peak UV index (UVI) could have trebled. ${ }^{4}$ Clearly this 
would have had disastrous consequences for human health and the environment. For example, at mid-northern latitudes, prior to the onset of ozone depletion the peak UVI values were approximately 10 . At those UVI levels, skin damage can occur for skinned people in approximately 15-20 minutes. Without the Montreal protocol, the peak UVI by 2065 may have been as high as 30, with a corresponding time for skin damage reducing as low as 5 minutes. The health consequences of such an increase would have been enormous. ${ }^{5}$ There is a large at-risk population in that latitude range, and it has been estimated that all other factors being equal, an increase in UV of 1\% corresponds to an increase in the incidence of skin cancer of $2-3 \%{ }^{6}$

On the other side of the ledger, recent research has shown that there is a beneficial side to UV through the production of vitamin D in the skin, and that at mid to high latitude site wintertime levels of UV are currently insufficient to maintain optimal levels of blood serum vitamin D. Humans of course have the capacity to modify their behaviour to minimise the risks and maximise possible benefits from UV exposure. However, the capacity of plants and animals and the environment to respond is much more limited.

Aside from the issues of ozone depletion and its possible recovery in the decades ahead, the future world will also be influenced by climate change. In addition to the expected increased concentrations of GHGs such as $\mathrm{CO}_{2}, \mathrm{CH}_{4}$, and $\mathrm{N}_{2} \mathrm{O}$, which are all currently increasing at 2-3\% per decade, and which could in turn influence future ozone concentrations in ways that may not be fully understood, we should also expect changes in cloud cover and aerosols. Changes in these can have important effects on surface UV irradiances. It is predicted (with low confidence) that cloud cover will increase at high latitudes but decrease at low latitudes. ${ }^{7}$ This will lead to decreases in UV in regions where is already low, but increases in UV in regions where it is already high. ${ }^{3}$ Future aerosol extinctions are open to speculation and will depend on factors such as population density, economic activity, the availability of fossil fuels, and environmental regulations.

Here we focus on predictions of clear sky UV under unpolluted skies, thus representing the maximum possible UV doses that may be expected in the future. We discuss the health implication of these expected future changes compared with those that would have occurred without the Montreal protocol.

\section{Method}

Details of the Goddard Earth Observing System chemistry-climate model (GEOSCCM) and simulations have been reported elsewhere. ${ }^{48}$ GEOSCCM is a fully coupled model in the radiation, chemistry, and dynamics. The model has a horizontal resolution of $2^{\circ}$ latitude by $2.5^{\circ}$ longitude with 55 vertical levels up to $0.01 \mathrm{hPa}(80$ $\mathrm{km}$ ). The model not only predicts ozone levels, but also changes of atmospheric temperatures, winds, radiation, and a multitude of other chemical species.

The "world avoided" is simulated using a scenario in which ozone depleting substances (ODSs) increase 3\% per year beginning in 1974, ${ }^{1}$ while the "expected future" is simulated with observed ODS levels to 2002 and then projected decreases of ODSs through the remainder of the century (scenario $\mathrm{Ab}$ from ref ${ }^{9}$ ). The first three simulations have been described elsewhere. " 10 The "expected future" is simulated with a combination of the reference past simulations from $1950-1995$, , the reference 
future from $2005-2100,{ }^{12}$ and a linear combination of the two simulations in the $1996-$ 2004 overlapping period.

We note that although GEOSCCM represents the current state-of-the-art, and compares well with other models, ${ }^{13},{ }^{14}$ it does not include tropospheric chemistry, which leads to uncertainties because change in future ozone column amounts. Tropospheric total ozone is tied to climatological values. However, the tropospheric contribution to the total column of ozone is typically less than $10 \%$. The model result is also sensitive to changes in sea surface temperature. ${ }^{15} \mathrm{We}$ also note that the GEOSCCM ozone fields are biased high, ${ }^{16}$ because the predicted ozone amounts are too large in the lower stratosphere. We have good confidence in the transport processes in the model, and speculate that there may be a small problem in the ozone loss rates in the lower stratosphere. In addition, model dynamics and temperatures are uncertain. The GCM has a problem with a "late-breakup" of the southern hemisphere winter polar vortex. This is a generic problem with models, and is rather poorly understood at present. Volcanic effects, the quasi-biennial oscillation, and solar variability are also omitted from these GEOSCCM simulations. The omission of these forcings reduces the year-to-year variability, especially in the tropics, but the omission does not effect ozone changes resulting from the slow variations of ODSs and GHGs.

The total column amounts of ozone for each grid point of GEOSCCM were then used in a radiative transfer model to calculate the daily clear-sky maximum in sunburning UV irradiance, expressed in terms of the UV Index (UVI) ${ }^{*}$. This calculation made use of a pre-calculated lookup table of UVI as a function of ozone and SZA. The look-up table was generated from the "tuv" radiative transfer model ${ }^{18}$ using the 8-stream DISORT option, ${ }^{19}$ which has been well validated against measurements. ${ }^{20}$

Adjustments were made for seasonal differences in Sun-Earth separation.

Adjustments were also made to represent the UVI values at the mean altitude for each grid point in the model, assuming a UV increase of 5\% per kilometre, which has been shown previously to be applicable for unpolluted conditions. ${ }^{21}$ No adjustments were made for geographical differences in albedo, which can have a marked effect on surface UV irradiances in snow-covered or ice-covered areas.

No corrections have been made to correct for the GEOSCCM biases in ozone. Consequently, the UVI values predicted by the model are approximately $10 \%$ less than from satellite, or ground based observations at clean sites. ${ }^{22,23}$ The observed year-to-year variability from the model however shows good agreement with observations, except in the case of volcanoes, the QBO, and solar forcing. ${ }^{8,13}$ As noted above, the GEOSCCM total ozone has a high polar bias in the 1950-1980 time period and matches observations reasonably well in the $1990-2007$ period. ${ }^{8}$ We estimated the errors in ozone changes (and UVI) by comparing the monthly means of the GEOSCCM simulation and the merged ozone data $\operatorname{set}^{24}$ for the 1978-2007 period at $70^{\circ} \mathrm{S}$ in December (a location and period that captures the effects of the Antarctic ozone hole). In the 1979-1985 period, the GEOSCCM total ozone is 10\% higher than the merged ozone, and the estimated UVI is $9 \%$ less. In the 1990-2007 period, the GEOSCCM total ozone is $1 \%$ higher than the merged ozone, and the estimated UVI is $1 \%$ lower

\footnotetext{
*UVI $=0.4 \times$ UV $_{\text {Ery, where UV }}$ is is the UV irradiance weighted by the CIE erythemal (i.e., "sunburning") action spectrum."
} 


\section{Results}

Figures 1 and 2 show snapshots of the estimated global fields of clear-sky UVI for March and November (respectively) in 1975 (before the onset of ozone depletion), 2020 (when ozone levels at mid latitudes are expected to have largely recovered from their minimum and to be close the 1975 levels), and 2065. Note that the UVI scale does not conform to the colours recommended by $\mathrm{WHO}^{25}$ (since they are defined only up to a maximum of $\mathrm{UVI}=10$ ).

In the expected future (left panels), the future UVI values remain close to those in 1975. But in world avoided (right panels), large areas would have been virtually uninhabitable by 2065 . The current maximum global UVI (UVI = 25), which is experienced only in the high altitude Altiplano region of South America in February, ${ }^{22}$ would be exceeded over half of the planet during both of these months, and would have been experienced for extended periods at mid-latitudes in each hemisphere during the corresponding summer months. During March, less than $10 \%$ of the Earth's surface has UVI values greater than 15 . However, by $202030 \%$ of the Earth's surface has values greater than 15, and by $206574 \%$ of the Earth's surface has values greater than 15. By March 2065, the peak UVI values would sometimes have exceed $\mathrm{UVI}=50$, more than double the present maximum, and peak UVI values at mid-latitudes would have been typically three times as high as in the period prior to the onset of ozone depletion. At latitudes poleward of $55^{\circ}$, increases from 1975 levels would have been greater than a factor of 5 . These huge changes are in marked contrast to what is expected due to the success of the Montreal Protocol, where future changes remain modest.

The November simulations (Figure 2) also show extreme changes of UVI. In the preozone hole period (top panel), a UVI of 4 is observed near $60^{\circ} \mathrm{S}$ in November. As the ozone hole developed, much higher UVI were observed in the Antarctic. ${ }^{26}$ The expected future (left panels) still show evidence of the effects of the ozone hole in 2020 (UVI > 4 pushing well onto the Antarctic continent), but the UVI returns to a more normal situation by 2065 . In contrast, the world avoided simulation (right panels) shows UVI $>11$ over Antarctica in 2020 and UVI ranging from 11-38 in 2065 (an average UVI of 27 at $60^{\circ} \mathrm{S}$ in November 2065). 


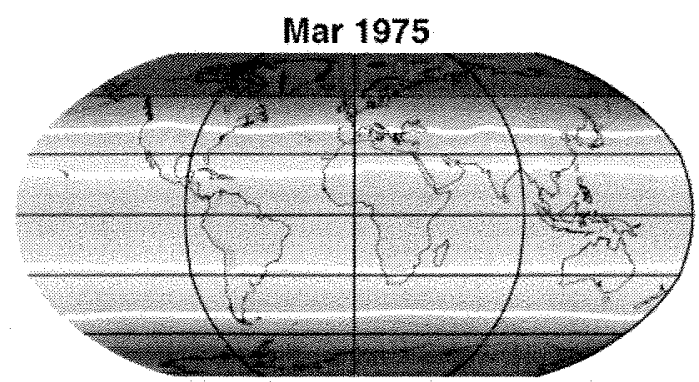

Expected Future

Mar 2020

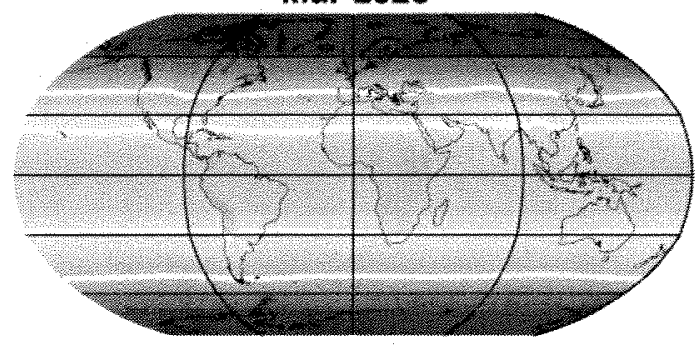

Mar 2065

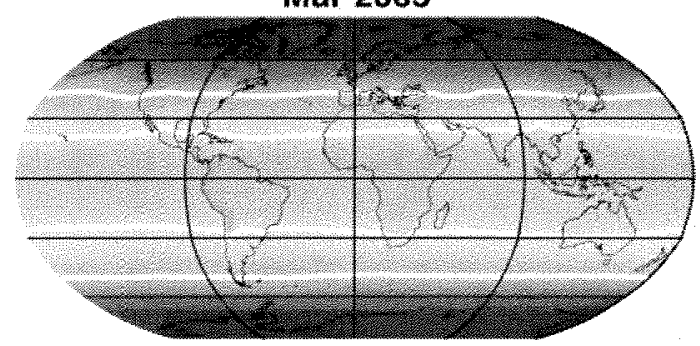

World Avoided

Mar 2020

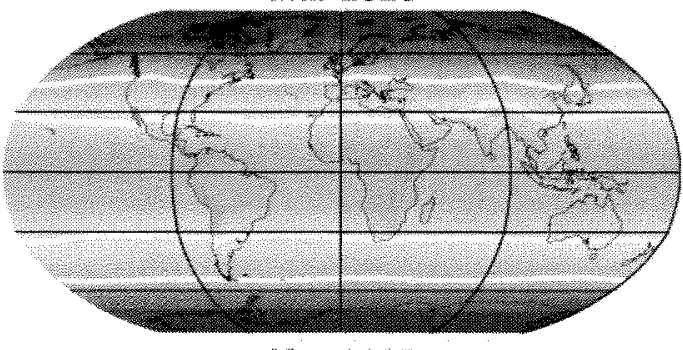

Mar 2065

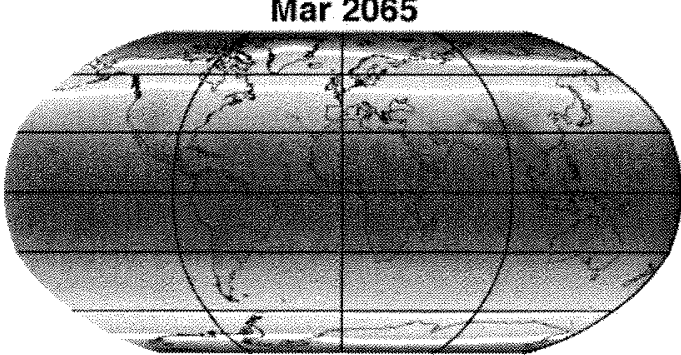

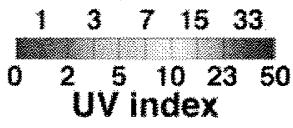

Figure 1. The calculated clear-sky UVI in March 1975, prior to the onset of ozone depletion, is shown at the top. The UV index for the "expected future" (left) is compared with that for "world avoided" (right) in March 2020 and 2065. The thick and thin white contour lines correspond to UVI values of 4 and 11 respectively. The simulations are described by ${ }^{4}$. 


\section{Nov 1975}
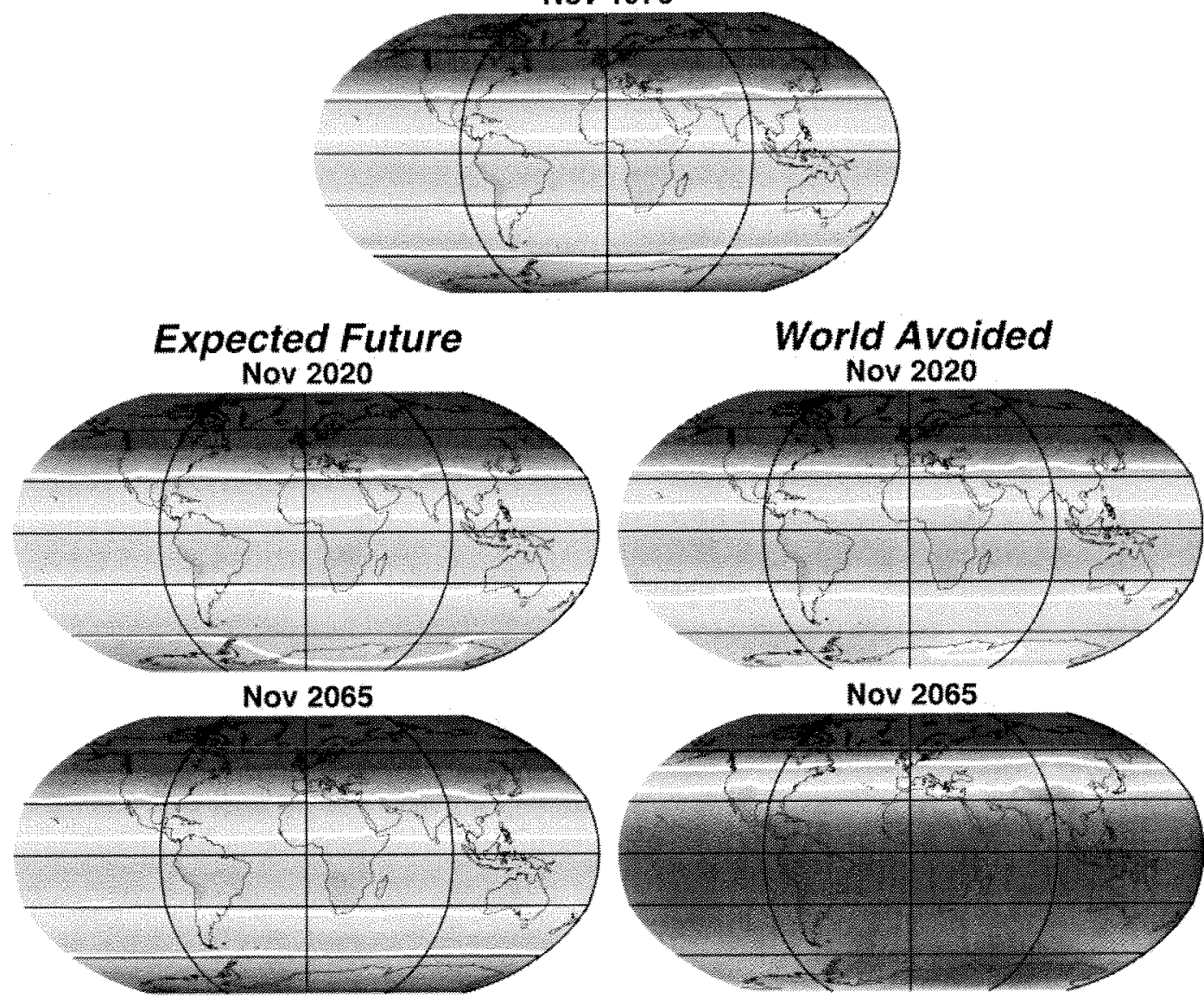

$$
\begin{gathered}
13 \quad 7 \quad 3533 \\
0.25102350 \\
0.5 V \text { index }
\end{gathered}
$$

Figure 2. As in Figure 1, but for November. 
From a health perspective, the annual UVI maxima and minima have relevance to the issues of sunburn and skin cancer in summer, and the issue of vitamin D deficiency in winter. These maxima and minima were calculated as a function of latitude for each year of the model calculations. In these simulations, the effect on UVI of altitude changes are small $(<4 \%)$. The high Antarctic topography results in a $4-14 \%$ increase of the zonal mean UVI, while the zonal mean increase is about $3.5 \%$ at the latitude of the Himalayan Plateau. At all other latitudes, the increase is less than $2 \%$.

Figures 3 shows time series of the zonal means in the peak (summer) monthly UVI as a function of latitude. The upper contour plot shows the predicted UVI maxima in the world avoided (without the Montreal Protocol), and the lower contour plot shows deviations in the UVI maxima from a 1974-1980 average for the expected future (with the Montreal Protocol). The model shows considerable year-to year variability, which is consistent with observations. These UVI variations have been reduced by application of a 1-2-1 Gaussian filter (i.e., a 1/2 amplitude of 4 years). The line graphs on the right show the season of the maxima (labelled by month - top right), and the mean UVI for the 1974-1980 expected future (bottom right), as functions of latitude respectively.

The summer UVI maxima has a strong latitudinal gradient, with highest values occurring near the equator, and currently reducing by about a factor of two at latitudes near $45^{\circ}$ in both hemispheres (see Figure 1, bottom right). These calculated maxima are lower than observed at clean sites, due to the high ozone bias in the model. Maximum values are higher in the SH than the NH, due to seasonal changes in SunEarth separation, and to lower summer ozone amounts in the SH. However, the asymmetry between $\mathrm{NH}$ and $\mathrm{SH}$ is also smaller than previously reported because extinctions from aerosols are excluded in these model calculations.

Without the Montreal Protocol, the peak UVI values would have increased substantially at all latitudes, particularly at high southern latitudes (Antarctica), where UVI values exceeding 20 would have occurred by 2050 . At mid latitudes, the peak values would have increased by a factor of three. The geographical extent of locations where the peak UVI remains less than 10 all year (i.e., currently where most white skinned population lives) would have become confined to latitudes greater than $60^{\circ} \mathrm{N}$ by mid-century. The maxima tend to occur at summer months when the sun is higher in the sky. However, at Polar latitudes the seasonal maximum is displaced somewhat towards the spring when ozone amounts tend to be lower. The asymmetry between the northern and southern hemisphere polar regions results from the asymmetry in the strength of the Brewer-Dobson circulation (BDC) between the two hemispheres, with a $7 \%$ contribution from seasonal differences in the Earth-Sun distance. The stronger northern hemisphere BDC in the winter-to-spring period resupplies ozone into the lower stratosphere, elevating total ozone levels, and thereby reducing the northern UVI in comparison to the southern UVI.

In the world expected (lower contour plot), the largest increases in UVI occur in the $\mathrm{SH}$, especially in the latitude range from $70-80^{\circ} \mathrm{S}$ (Antarctic ozone hole) from about 1990 to 2030 . They are currently near their highest, but are expected to reduce to levels lower than in 1980 by the end of the study period. In the tropics, changes in UVI are smaller, and there is a suggestion that UVI values will increase again after reaching a minimum in the mid $21^{\text {st }}$ century. 

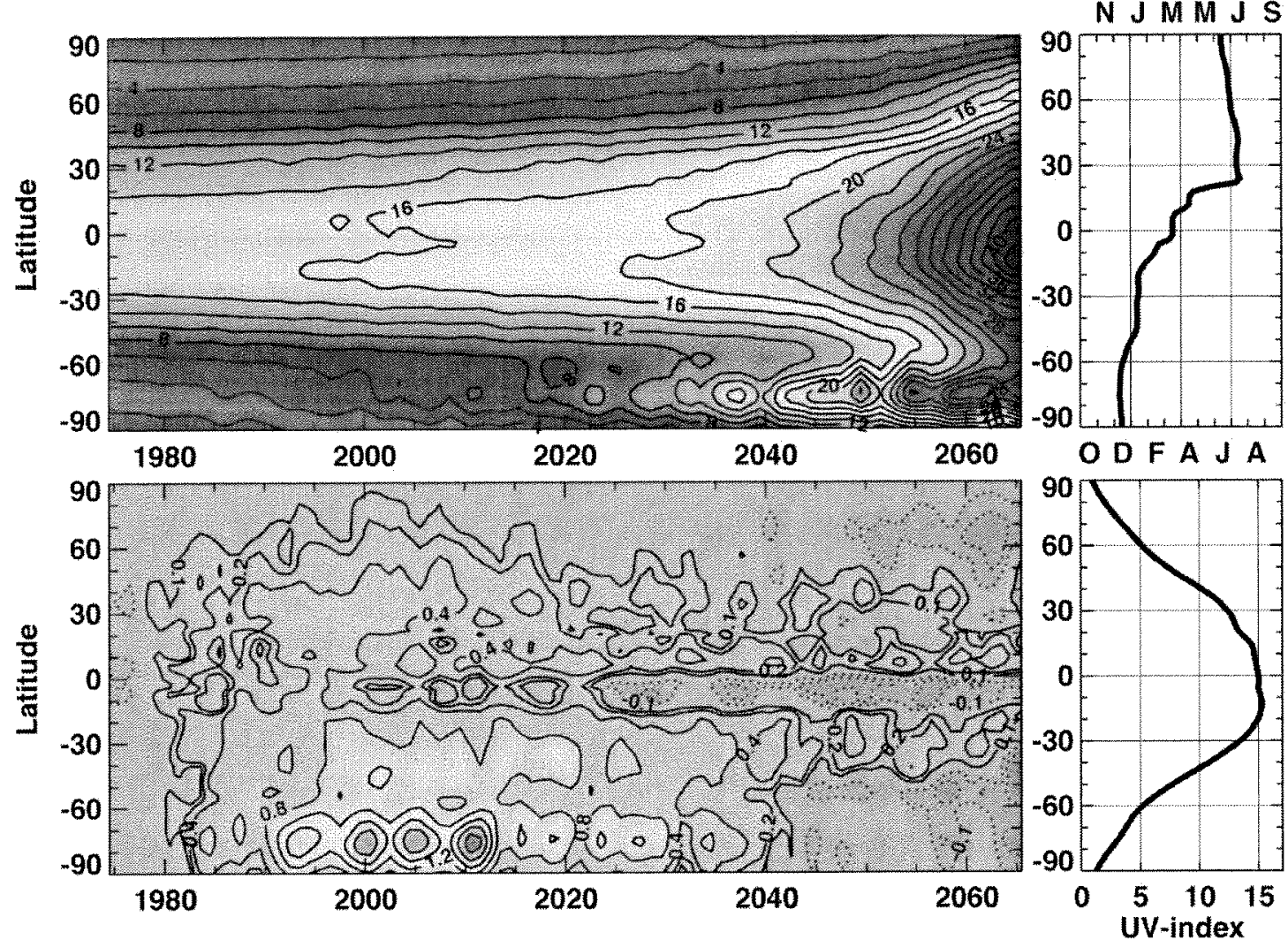

Figure 3. The upper panel represents the "World Avoided". The peak UVI as a function of latitude and year is shown in the contour plot on the left (with each contour line represents a change in UVI of 2), and the season of the maximum (month of year) for each latitude is shown on the right. The lower panel represents the "Expected Future". Means of the maxima for each latitude over the 1974-1980 period are shown on the right, and the deviations from those baseline values are shown in the contour plot on the left (contour line at $\pm 0.1, \pm 0.2, \pm 0.4, \pm 0.8 \ldots$, with no zero line shown). 
Figure 4 is equivalent to Figure 3, but shows the winter UVI minima, rather than the summer maxima. In this case the plots are restricted to latitudes $60^{\circ} \mathrm{S}$ to $60^{\circ} \mathrm{N}$, because minimum values remain small throughout the period at higher latitudes.

The winter UVI minima also has a strong latitudinal gradient, with highest values occurring near the equator, and currently reducing by about a factor of two at latitudes near $20^{\circ}$, and by a factor of 10 by latitude $45^{\circ}$ in both hemispheres. Again, these calculated maxima are lower than observed at clean sites, due to the ozone bias in the model. In contrast to the maxima, these UVI minima are higher in the NH than the $\mathrm{SH}$, again due to seasonal changes in Sun-Earth separation, and to lower winter ozone amounts in the NH.

Without the Montreal Protocol, the UVI minima would have increased substantially at all latitudes. By 2065 , even the annual UVI minima would have exceeded the current peak throughout most of the tropics, even at sea level. At latitude $45^{\circ}$, the minimum UVI would have increased by about a factor of five. In contrast to the seasonality for the maxima, at nearly all latitudes, the minima occur close to the winter solstice when the sun is lowest in the sky. The mid-winter UVI value of 1 is found at $44^{\circ}$ in both hemispheres in 1975, but in the world avoided, this mid-winter value of 1 is found at $57^{\circ}$. At the equator, the mid-winter minimum value increases from about 11.5 to 32 .

In the world expected (Fig. 4 lower left), the largest absolute increases in UVI occur in the tropics $\left( \pm 20^{\circ}\right)$, though relative changes are larger at high latitudes. According to the model, these winter minima are now lower than they were in the 1990s, and are expected to reduce further in the future, though these changes are rather small and are comparable with the historical year-to-year variability. A rapid decrease of UVI is apparent close to the equator in both Figures 3 and 4 for the 1990-2020 period. This UVI decrease is related to the rapid change of ozone depleting substances (ODSs) in the tropics (the entry zone for ODSs into the stratosphere) and the width of the upwelling in the tropics from the Brewer-Dobson circulation. In the expected future panel Figure 4 (bottom left), there appears to be a sharp gradient of UVI between $4{ }^{\circ} \mathrm{N}$ and $2^{\circ} \mathrm{N}$. This gradient is an artefact of the trends in different months for the minimum (see the sharp phase shift in the top right). 

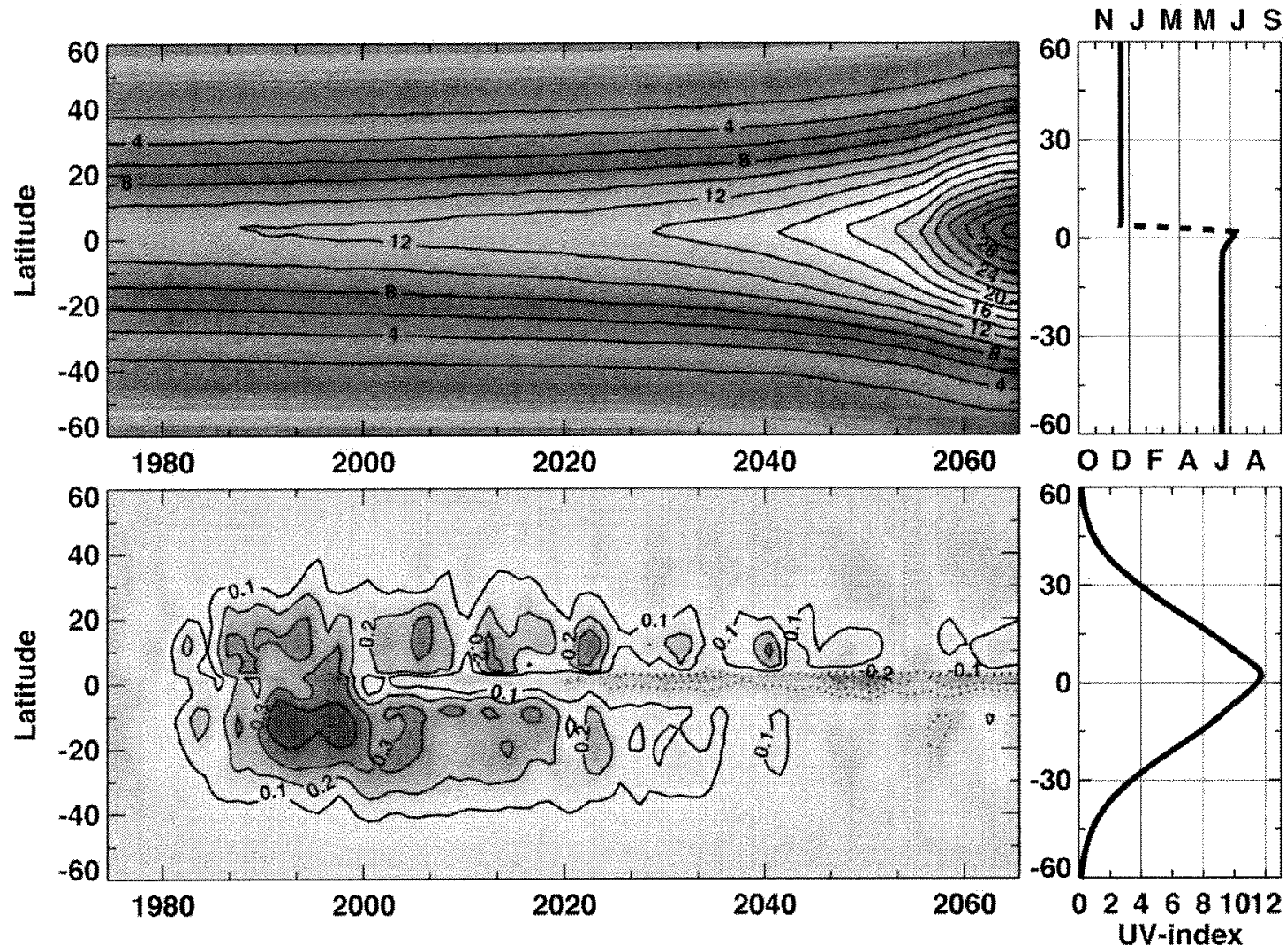

Figure 4. As for Figure 3, but for UVI minima rather than maxima. The upper panel represents the "World Avoided". The minimum noon UVI as a function of latitude and year is shown in the contour plot on the left, and the season of the minimum (month of year) for each latitude is shown on the right. The lower panel represents the "Expected Future". The 1974-1980 means of the minima for each latitude are shown on the right, and the deviations from those baseline values are shown in the contour plot (contours are shown for 0.1 UVI increments, with no zero line). The dashed line in the top right represents a sharp phase shift in the month between two adjacent model points. 
Figure 5 shows the seasonal variations in UVI for 2 different latitudes over 2 different decadal periods. The first period is the 1974-1984 period prior to the onset of significant ozone depletion. The second period is the 2045-2055 from the "world avoided" scenario. In each case the daily UVI values (calculated from daily total ozone and local noon clear sky conditions) are averaged over the 11 year period at the 144 longitudes in the model (i.e., from $0^{\circ}$ to $357.5^{\circ}$ at $2.5^{\circ}$ increments). In addition to these average values (solid line) the plots also show the daily minima and maxima (light shading), and the 25 and 75 percentile values (dark shading). For example, on June 1 at $46^{\circ} \mathrm{N}$ in the $1974-1984$ period there are 1584 UVI values (144 longitudes $\mathrm{x}$ 11 years). The lowest value is about $5.5,25 \%$ of the values are below 7 , the average is about $7.5,75 \%$ of the values are below 8.1 (i.e., $50 \%$ of the UV index values are found between 7 and 8.1), and the record high is about 10.7. The SH plot is shifted 6 months for comparison to the NH. The same UV index scale is used for both plots.

For the 2045-2055 world avoided scenario, there is much higher variability, especially in the early summer. The peak UVI values also occur earlier, especially in the southern hemisphere. At $46^{\circ} \mathrm{N}$, the appearance of a UVI of 5 occurs 2.5 months earlier in the world avoided and disappears about 2 months later (see grey horizontal line). The mid summer high increases from about 8.5 to 20 . The lowest mid summer 2045 2055 values exceed the highest values estimated for the $1974-1984$ period. At $46^{\circ} \mathrm{N}$, the mid summer maximum value of 8.5 now occurs in late February and is gone in mid October. At $46^{\circ} \mathrm{S}$, the behaviour is comparable, albeit with higher UV index values than in the $\mathrm{NH}$. However, the large "acute" events are extremely prominent in the SH. This is most probably due to fragments of ozone-poor air being advected to mid-latitudes. The distributions in both hemispheres are completely separated: even in the winter they have no overlap.

Of course, for the 2055-2065 period, the behaviour would be even more extreme (see Figure 2). 

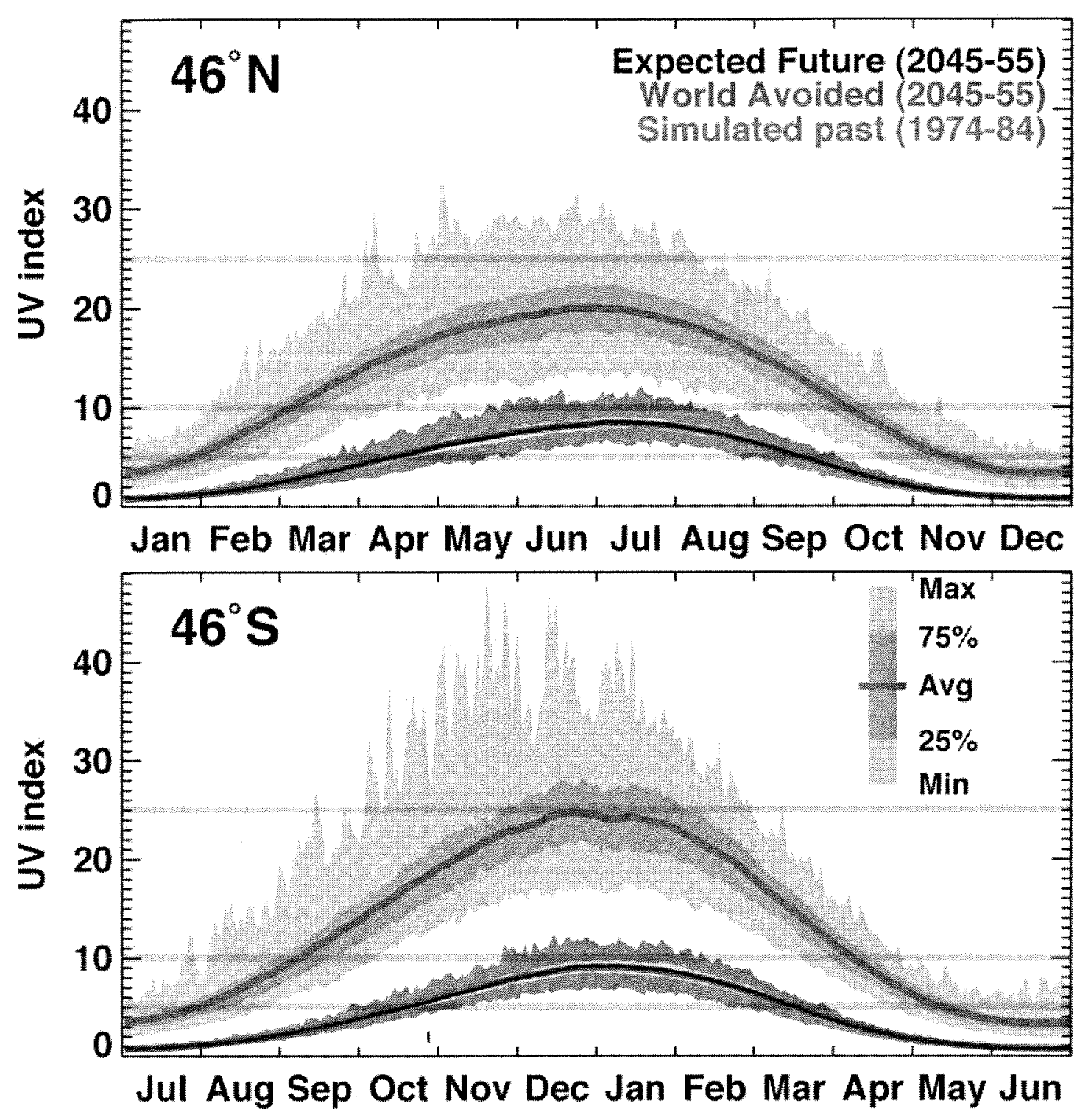

Figure 5. UVI at mid-northern and southern latitudes as a function of season for the two scenarios: the world avoided in 2050 (blue) and the expected future (black). The dark shaded areas in these scenarios show the inter-quartile range, and the lighter shading represents the full range of variabilities. The red line shows the 1974-84 average of the simulated past. This 1974-1984 simulated past is almost completely obscured by the 2045-55 expected future because ozone levels have returned to approximately their 1980 values by 2050 . 


\section{Discussion}

What are the implications of these projected UV changes for skin cancer and vitamin D deficiency? The response time between UV exposure and sunburn, which is thought to be a risk factor for skin cancer is approximately 1 day, although the development of skin cancer itself is typically over decadal time scales. The increases in the incidence rates of skin cancer from the "world avoided" would have been dramatic since, assuming other factors are equal, an increase in UV of $1 \%$ corresponds to an increase in the incidence of skin cancer of $2-3 \%{ }^{5,6}$. If that rate applies for these very large changes in UV, then the rates of skin cancer following UV exposures in the mid $21^{\text {st }}$ century could have been amplified by a factor of more than 500 . If we take a further step and assume that a similar relationship holds for melanoma skin cancer, then for countries with high mortality from skin cancer, such as Australia and New Zealand, an increase from the present mortality rate of approximately 7 per 100,000 to over 3,500 per 100,000 may have been expected.

On the other hand, the lifetime of vitamin $\mathrm{D}$ in the body has been variously estimated as between 2 weeks and 13 weeks for an e-folding time (i.e., the time taken to decay to $1 / \mathrm{e}$ or 0.368 of its initial value). ${ }^{27-29}$. Thus, in addition to changes in the minimum UV irradiances, changes in the seasonal duration for which the UV remains below some threshold ${ }^{30}$ may also be important. As shown by Figure 4, the "world avoided" could have been of some benefit from a vitamin D perspective. However, by the same token, the future expectation from the "world expected" does not represent a significant increased risk compared with the present (see Figure 3). In the world expected, wintertime UVI values are only slightly lower than at present, and the period of the minima is not changed significantly.

Although there has been some dispute about the point recently, ${ }^{31}$ the current recommendation is that there is no effective vitamin $\mathrm{D}$ production for several months at all latitudes pole-ward of $40^{\circ} \mathrm{N} .^{32}$ This corresponds to periods when the UVI falls below approximately 1 . In the world avoided, the geographical extent of locations where the minimum UVI always remains greater than 1 (i.e., where vitamin D production from UV should be possible,) would have increased markedly from all latitudes less than $45^{\circ}$ to all latitudes less than $60^{\circ}$ by mid-century, and the minimum UVI at latitude $45^{\circ}$ would have increased by a factor of three. In the world avoided simulation, the area coverage of regions with local noon UVI values less than 1 during the winter solstice (including polar night) decreases from about $15 \%$ of the Earth's surface in the 1970 s to about $8 \%$ by 2065 (i.e., mainly the polar night region). From the standpoint of vitamin D production, such increases in wintertime UVI are marginally advantageous

Unless strict sun avoidance were practised, it seems likely that the benefits from increased UV in winter are likely to have been small compared with the consequences of the hugely increased UV in spring, summer, and autumn. Furthermore, at many mid-latitude sites, the increases in UV would have been sufficient to lead to risks of skin damage even in the winter months. It is highly likely that behavioural changes would also be significant by mid-century. Since humans are typically exposed to only a very small fraction of the available UV, ${ }^{33,34}$ changes in UV exposures due to behavioural changes have the capacity to far outweigh the environmental effects of changes in wintertime UV. However, that is not the case for 
excess summertime exposures, or for other environmental effects where the options for modifying exposure to UV are more limited.

In the expected future scenario, UV is expected to decrease at mid to high latitudes, including the regions where skin cancer is most prevalent. The future risk of skin cancer induced by UV exposure may therefore be expected to decrease. At low latitudes, there may be a small increased risk, but this may be offset by behavioural changes caused by the discomfort of outdoor exposures at high temperatures. Any decreases in wintertime UV are expected to be relatively small, so any increased risk of insufficient vitamin D production during winter would also be correspondingly small.

We note however, that in a future world, the effects of climate change must also be considered. Possible effects include increased cloudiness at high latitudes, and decreased cloudiness at low latitudes. ${ }^{7}$ Changes in surface albedo may be important in the future as a result of climate change, with retreats of glaciated regions to higher altitudes and latitudes. As has been shown previously, surfaces with high albedo have significant effects on UV irradiances, ${ }^{35-37}$ and can influence UV irradiances up to 40 $\mathrm{km}$ from the ice margins. ${ }^{37}$ These factors would further tend to reduce the UV irradiances in places where it is currently low, and increase it at places where it is currently high. Consequently, these potential effects of climate change would have adverse effects on both skin cancer incidence (a mid to low latitude issue) and vitamin $\mathrm{D}$ deficiency (a mid to high latitude issue).

The calculations presented here are model predictions. These simulations are based upon a single greenhouse gas scenario, and the expected future of ozone depleting substances is also based upon a single scenario. Although the expected future is considered a likely scenario, reality may differ appreciably, especially when possible political and technological events are factored into our assessments.

\section{Conclusions}

The Montreal Protocol is an agreement that has successfully phased down the production and consumption of ozone depleting substances (ODSs) such as chlorofluorocarbons and halons. This study has estimated erythemal UV changes that result from the implementation of the Protocol (the expected future) and UV levels that would have been seen without a Montreal Protocol (the world avoided). Our estimated UV indices that have been corrected for altitude effects and Earth-Sun distance using model simulations of total ozone

This study has expanded on the UV increases discussed previously, which focussed mainly the changes of stratospheric ozone, the dynamics and chemistry of the stratosphere. Based on these calculations of clear-sky erythemal UV irradiances, the effects of the Montreal Protocol have been hugely beneficial to preventing high levels of surface UV radiation. In the world avoided, UV levels would have tripled over their 1975 levels. Between 1975 and 2065, the average December $74^{\circ} \mathrm{S}$ UVI (midsummer) increases from an average of 3 to 33 . In the NH, the June $74^{\circ} \mathrm{N} \mathrm{UVI}$ increases from 3 to 13 . In addition to the maximum value of the UVI, the minimum UVI also increases substantially in the world avoided. At the equator, the mid-winter minimum value increases from about 11.5 to 32 between 1975 and 2065 . 
Simulations of our expected future show a steady decline of UVI in the 2010 through 2065. UVI increased in the 1980-2000 period by only a few tenths. The largest increases occurred at Antarctic latitudes during the Austral spring and summer as a result of the ozone hole.

The effects of the Montreal Protocol have also been hugely beneficial to health risks, such as sunburn and skin cancer, which are associated with high UV. A potentially positive aspect of a world avoided is the increase of vitamin $\mathrm{D}$ production from increased UV, particularly at mid-to high latitudes in mid-winter. The seasonal extent of this issue would have been reduced, and the minimum latitude at which this becomes a problem would have been displaced significantly towards the poles. However, production of vitamin D is strongly dependent on other factors as well, such as the area of skin expososed, and the time spent outdoors, which in many cases would dominate.

The model used is this study to estimate total ozone is strictly a stratospheric coupled cloud chemistry model. This limits the study, since the effects on tropospheric chemistry of the increased penetration of UV to the troposphere cannot be simulated. The erythemal estimates in this study are somewhat limited by the ommision of cloud effects and albedo, and the changes of those parameters might occur in a world avoided simulation. While changes of greenhouse gases such as $\mathrm{CO} 2, \mathrm{~N} 2 \mathrm{O}$, and $\mathrm{CH} 4$ are included in the model, the feedback of ODS increases on the tropospheric climate are not properly simulated because of the use of conventional climate change sea surface temperatures used in the model. Finally, increased UV at the surface would almost certainly alter Earth's biota, and thereby change greenhouse gase levels and hydrocarbon levels. 


\section{References}

1 G. J. M. Velders, S. O. Andersen, J. S. Daniel, D. W. Fahey and M. McFarland, The importance of the Montreal Protocol in protecting climate, PNAS, 2007, 104, 4814-4819.

2 WMO, Scientific Assessment of Ozone Depletion: 2010, Vol. Global Ozone Research and Monitoring Project - Report No. ??, Geneva, 2011, in press.

3 UNEP, Environmental effects of ozone depletion and its interactions with climate change: 2010 assessment, Photochem. Photobiol. Sci., 2011, in press.

4 P. A. Newman, L. D. Oman, A. R. Douglass, E. L. Fleming, S. M. Frith, M. M. Hurwitz, S. R. Kawa, C. H. Jackman, N. A. Krotkov, E. R. Nash, J. E. Nielsen, S. Pawson, R. S. Stolarski and G. J. M. Velders, What would have happened to the ozone layer if chlorofluorocarbons (CFCs) had not been regulated?, Atmos. Chem. Phys., 2009, 9, 2113-2128.

5 H. Slaper, G. J. M. Velders, J. S. Daniel, F. R. de Gruijl and J. C. van der Leun, Estimates of ozone depletion and skin cancer incidence to examine the Vienna convention achievements, Nature, 1996, 384, 256-258.

6 UNEP, Environmental effects of ozone depletion: 1994 assessment, UNEP, Nairobi, 1994.

$7 \quad$ K. E. Trenberth and J. T. Fasullo, Global warming due to increasing absorbed solar radiation, Geophys. Res. Lett., 2009, 36, doi:10.1029/2009GL037527.

8 S. Pawson, R. S. Stolarski, A. R. Douglass, P. A. Newman, J. E. Nielsen, S. M. Frith and M. L. Gupta, Goddard Earth Observing System chemistry climate model simulations of stratospheric ozone - temperature coupling between 1950 and 2005, J. Geophys. Res., 2008, 113, 10.1029/2007JD009511.

9 WMO, Scientific Assessment of Ozone Depletion: 2002, Vol. Global Ozone Research and Monitoring Project - Report No. 47, Geneva, 2003.

10 L. D. Oman, D. Plummer, D. W. Waugh, J. Austin, J. Scinocca, A. R. Douglass, R. J. Salawitch, T. Canty, H. Akiyoshi, S. Bekki, P. Braesicke, N. Butchart, M. Chipperfield, D. Cugnet, S. Dhomse, V. Eyring, S. Frith, S. C. Hardiman, D. Kinnison, J. F. Lamarque, E. Mancini, M. Marchand, M. Michou, O. Morgenstern, T. Nakamura, J. E. Nielsen, D. Olivie, G. Pitari, J. Pyle, E. Rozanov, T. G. Shepherd, K. Shibata, R. S. Stolarski, H. Teyssedre, W. Tian and Y. Yamashita, Multi-model assessment of the factors driving the ozone evolution over the $21^{\text {st }}$ century, Journal of Geophysical Research, 2010, in press.

11 V. Eyring, N. Butchart, D. W. Waugh, H. Akiyoshi, J. Austin, S. Bekki, G. E. Bodeker, B. A. Boville, C. Brühl, M. P. Chipperfield, E. Cordero, M. Dameris, M. Deushi, V. E. Fioletov, S. M. Frith, R. R. Garcia, A. Gettelman, M. A. Giorgetta, V. Grewe, L. Jourdain, D. E. Kinnison, E. Mancini, E. Manzini, M. Marchand, D. R. Marsh, T. Nagashima, P. A. Newman, J. E. Nielsen, S. Pawson, G. Pitari, D. A. Plummer, E. Rozanov, M. Schraner, T. G. Shepherd, K. Shibata, R. S. Stolarski, H. Struthers, W. Tian and M. Yoshiki, Assessment of temperature, trace species, and ozone in chemistry-climate model simulations of the recent past, Journal of Geophysical Research, 2006, 111.

12 V. Eyring, D. W. Waugh, G. E. Bodeker, E. Cordero, H. Akiyoshi, J. Austin, S. R. Beagley, B. A. Boville, P. Braesicke, C. Brühl, N. Butchart, M. P. Chipperfield, M. Dameris, R. Deckert, M. Deushi, S. M. Frith, R. R. Garcia, A. Gettelman, M. A. Giorgetta, D. E. Kinnison, E. Mancini, E. Manzini, D. R. 
Marsh, S. Matthes, T. Nagashima, P. A. Newman, J. E. Nielsen, S. Pawson, G. Pitari, D. A. Plummer, E. Rozanov, M. Schraner, J. F. Scinocca, K. Semeniuk, T. G. Shepherd, K. Shibata, B. Steil, R. S. Stolarski, W. Tian and M. Yoshiki, Multi-model projections of ozone recovery in the $21^{\text {st }}$ century, Journal of Geophysical Research, 2007, 112.

13 SPARC CCMVal, SPARC Report on the Evaluation of Chemistry-Climate Models, V. Eyring, T. G. Shepherd, D. W. Waugh (Eds.), SPARC Report No. 5, WCRP-132, WMO/TD-No. 1526, hitp: Wwwatmosp phvics utoronto.ca/SPARC, 2010.

14 V. Eyring, I. Cionni, G. E. Bodeker, A. J. Charlton-Perez, D. E. Kinnison, J. F.Scinocca, D. W. Waugh, H. Akiyoshi, S. Bekki, M. P. Chipperfield, M. Dameris, S. Dhomse, S. M. Frith, H. Garny, A. Gettelman, A. Kubin, U. Langematz, E. Mancini, M. Marchand, T. Nakamura, L. D. Oman, S. Pawson, G. Pitari, D. A. Plummer, E. Rozanov, T. G. Shepherd, K. Shibata, W. Tian, P. Braesicke, S. C. Hardiman, J. F. Lamarque, O. Morgenstern, J. A. Pyle, D. Smale and Y. Yamashita, Multi-model assessment of ozone return dates and ozone recovery in CCMVal-2 models, Atmospheric Chemistry and Physics, 2010, 10, 10, 9451-10,9472.

15 J. Austin and R. J. Wilson, Sensitivity of polar ozone to sea surface temperatures and halogen amounts, J. Geophys. Res., 2010, 115, 10.1029/2009JD013292.

16 S. Pawson, R. S. Stolarski, A. R. Douglass, P. A. Newman, J. E. Nielsen, S. M. Frith and M. L. Gupta, Goddard Earth Observing System chemistry climate model simulations of stratospheric ozone temperature coupling between 1950 and 2005, J. Geophys. Res., 2008, 113, 10.1029/2007JD009511.

17 A. F. McKinlay and B. L. Diffey, A reference action spectrum for ultra-violet induced erythema in human skin, in Human Exposure to Ultraviolet Radiation: Risks and Regulations eds.: W. F. Passchier and B. F. M. Bosnajakovic, Elsevier, Amsterdam, 1987, pp. 83-87.

18 S. Madronich and S. Flocke, Theoretical estimation of biologically effective UV radiation at the earth's surface, in Solar Ultraviolet Radiation. NATO, Series I: Advanced Study Institute, Vol. 52 eds.: C. S. Zerefos and A. F. Bais, Springer, Berlin, 1995, pp. 23-48.

19 K. Stamnes and R. A. Swanson, A new look at the discrete ordinate method for radiative transfer calculations in anisotropically scattering atmospheres, Journal of the Atmospheric Sciences, 1981, 38, 387-399.

20 J. Zeng, R. McKenzie, K. Stamnes, M. Wineland and J. Rosen, Measured UV spectra compared with discrete ordinate method simulations, Journal of Geophysical Research, 1994, 99, 23019-23030.

21 R. L. McKenzie, P. V. Johnston, D. Smale, B. Bodhaine and S. Madronich, Altitude effects on UV spectral irradiance deduced from measurements at Lauder, New Zealand and at Mauna Loa Observatory, Hawaii, J. Geophys. Res., 2001, 106, 22845-22860.

22 R. L. McKenzie and J. B. Liley, Balancing Risks and Benefits of UV radiation, in UV Radiation in Global Change: Measurements, Modeling and Effects on Ecosystems eds.: W. Gao, D. L. Schmoldt and J. R. Slusser, Tsinghua University Proess and Springer-Verlag, Beijing/New York, 2010, pp. $21-47$ of 544 . 
23 R. L. McKenzie, G. E. Bodeker, G. Scott and J. Slusser, Geographical differences in erythemally-weighted UV measured at mid-latitude USDA sites, Photochemical \& Photobiological Sciences, 2006, 5, 343-352.

24 R. S. Stolarski and S. M. Frith, Search for evidence of trend slow-down in the long-term TOMS/SBUV total ozone data record: the importance of instrument drift uncertainty, Atmos. Chem. Phys., 2006, 6, 4057-4065.

25 WHO, Global solar UV Index: A practical guide, World Health Organisation (WHO), World Meteorological Organisation (WMO), United Nations Environment Program (UNEP), and International Commission on NonIonising Radiation Protection (ICNRP), Geneva, 2002.

26 G. Bernhard, C. R. Booth and J. C. Ehramjian, Climatology of ultraviolet radiation at high latitudes derived from measurements of the national Science Foundation's spectral irradiance monitoring network, in UV Radiation in Global Change: Measurements, Modeling and Effects on Ecosystems eds.: W. Gao, D. L. Schmoldt and J. R. Slusser, Tsinghua University Press, Beijing and Springer, New York, 2010, p. 544.

27 A. Zittermann, Vitamin D in preventive medicine: are we ignoring the evidence?, British Journal of Nutrition, 2003, 89, 552-572.

28 F. Wu, T. Staykova, A. Horne, J. Clearwater, R. Ames, B. Mason, B. OrrWalker, G. Gamble, M. Scott and I. Reid, Efficacy of an oral, 10-day course of high-dose calciferol in correcting vitamin D deficiency, The New Zealand Medical Journal, 2003, 116, 1179 ISSN 11758716.

29 J. Livesey, P. Elder, J. Ellis, R. McKenzie, B. Liley and C. Florkowski, Seasonal variation in vitamin $D$ levels in the Canterbury population in relation to available UV radiation, New Zealand Medical Journal, 2007, 120, http:/www.nzma.org.nz/joumal/120-1262/2733/.

30 O. Engelsen, M. Brustad, L. Aksnes and E. Lund, Daily duration of vitamin D synthesis in human skin with relation to Latitude, Total Ozone, Altitude, ground cover, aerosols and cloud thickness, Photochemistry and Photobiology, 2005, 81, 1287-1290.

31 R. L. McKenzie, J. B. Liley and L. O. Björn, UV Radiation: Balancing Risks and Benefits, Photochemistry and Photobiology, 2009, 85, 88-98.

32 A. R. Webb, L. Kline and M. F. Holick, Influence of season and latitude on the cutaneous synthesis of vitamin D3: Exposure to winter sunlight in Boston and Edmonton will not promote vitamin D3 synthesis in human skin, Journal of Clinical Endocrinology and Metabolism, 1988, 67, 373-378.

33 C. Y. Wright, A. I. Reeder, G. E. Bodeker, A. Gray and B. Cox, Solar UVR exposure, concurrent activities and sun-protective practices among primary schoolchildren, Photochemistry and Photobiology, 2007, 83, 749-758.

34 P. Knuschke, I. Unverricht, G. Ott and M. Jansen, Personenbezogene messung der UV-Exposition von Arbeitnehmern im freien, Bundesanstalt fur Arbeitsschutz und Arbeitsmedian (BAUA) Report No., Dortmund/Berlin/Dresden, p. 195. Available from:

35 A. Kylling, A. Dahlback and B. Mayer, The effect of clouds and surface albedo on UV irradiances at a high latitude site, Geophysical Research Letters, 2000, 27, 1411-1414.

36 A. Kylling, T. Persen, B. Mayer and T. Svenøe, Determination of an effective spectral surface albedo from ground-based global and direct UV irradiance measurements, Journal of Geophysical Research, 2000, 105, 4949-4959. 
37 M. Degünther, R. Meerkötter, A. Albold and G. Seckmeyer, Case study of the influence of inhomogeneous surface albedo on UV irradiance, Geophysical Research Letters, 1998, 25, 3587-3590. 